\title{
¿Quo vadis cellula?
}

\author{
Eduardo Kessi C. ${ }^{1}$ \\ ${ }^{1}$ Departamento de Ciencias Biológicas Animales, Facultad de Ciencias Veterinarias y Pecuarias, \\ Universidad de Chile. Email: $\underline{\text { ekessi@uchile.cl }}$
}

\begin{abstract}
Resumen
El uso de procedimientos de alto rendimiento en datos (high-throughput) que pueden analizarse a la luz de modelos apropiados, y la posibilidad del análisis al nivel de una sola molécula (single-molecule level) revelan novedades respecto de nuestra comprensión de la función y organización biológicas. ¿Influye la biología de sistemas en nuestra visión actual de la célula?
\end{abstract}

Palabras Clave: Célula, Biología de Sistemas, Modelos.

\section{Introducción}

Hace ya casi cuarenta años Maturana y Varela afirmaron que "Cuando un espacio se divide en dos, nace un universo: Se define una unidad. La descripción, la invención y la manipulación de unidades están en la base de toda indagación científica" (Maturana y Varela, 1998). En el mundo de lo vivo la unidad es indudablemente la célula. No es ciertamente la célula una unidad surgida de alguna teoría, o una manera de concebir el mundo, (como es el caso del átomo) sino más bien de la experiencia, y por cierto implica la difícil concesión de excluir a los virus, cuyo status es motivo hoy de intensa investigación por cuanto se les reconoce un papel destacado en el curso de la evolución de los organismos vivos. En tanto la unidad, la célula ha demostrado su enorme potencial para ayudarnos a comprender qué es aquello que distinguimos como vivo precisamente porque podemos describirla $\mathrm{y}$ manipularla. En esa dirección una serie de métodos, la mayoría de ellos provenientes de la tradición de la química y de la física han sido de enorme utilidad pero, precisamente por su origen, han impedido hacer las preguntas apropiadas respecto de la esencia de lo que una célula es. En palabras de Varela, "el problema de la autonomía de lo vivo es central y hay que cernirlo en su forma mínima, en la caracterización de la unidad viviente" (Maturana y Varela, 1998) ¿Puede una visión más integradora ayudar a ese respecto?
La Biología de Sistemas (Systems Biology) es un término que se usa para referirse a campo de estudio interdisciplinario, basado en la biología, que se centra en las interacciones complejas que ocurren en los organismos vivos. Un objetivo declarado por quienes se dedican a este campo, es descubrir y modelar las propiedades emergentes de un sistema, cuya descripción teórica sólo es posible mediante el uso de técnicas que son del ámbito de la biología de sistemas.

Naturalmente, la biología de sistemas resulta ser compleja. En efecto, se la puede considerar como un campo de estudio, por ejemplo el estudio de los componentes de un sistema biológico y de las interacciones de esos componentes que originan las funciones y comportamientos de ese sistema particular (las enzimas y los metabolitos en una vía metabólica, evaluados por ej. mediante el Análisis del Control del Metabolismo- MCA, un derivado de lo que originalmente se conoció como la Teoría del Control del Flujo). Una siguiente manera de mirar a la biología de sistemas es considerarla un paradigma (en el sentido de Kuhn) definido como la antítesis del reduccionismo. A este respecto una distinción útil respecto de esos paradigmas puede escribirse como lo siguiente:

"El enfoque reduccionista ha identificado con éxito la mayor parte de los componentes y muchas de las interacciones, pero, por desgracia, no ofrece conceptos convincentes o métodos para entender cómo surgen las propiedades del sistema ... la 
pluralidad de causas y efectos en las redes biológicas puede abordarse de mejor manera mediante la observación, a través de medidas cuantitativas, de varios componentes al mismo tiempo y por la integración de datos rigurosos usando modelos matemáticos " (Sauer et al., 2007)

"La biología de sistemas... es más constructiva que analítica, más integradora que reductiva. Requiere que desarrollemos formas de pensar acerca de la integración tan rigurosas como nuestros programas reduccionistas, pero diferentes.... Esto significa cambiar nuestra filosofía, en el más amplio sentido de la palabra " (Noble, 2006)

Aun cuando se ha descrito que la biología de sistemas es el estudio del comportamiento de la organización y los procesos biológicos complejos en términos de sus constituyentes moleculares (Kirschner, 2005), desde una perspectiva más operacional, la biología de sistemas puede considerarse como un conjunto de protocolos operativos que se usan para realizar investigación, esto es un ciclo compuesto por 1) una teoría, 2) modelamiento analítico mediante procesadores, 3) proposición de hipótesis comprobables, 4) comprobación experimental de las hipótesis propuestas y 5) uso de la descripción adquirida de las células, o procesos celulares a los que se refiere, para refinar el modelo propuesto, o la teoría que lo sostiene(ver Figura 1). Debido a que el objetivo es generar un modelo de las interacciones que se producen en el sistema considerado, los procedimientos experimentales más adecuados para la biología de sistemas son aquellos que abordan el sistema de la manera más completa posible. En este sentido, la transcriptómica, la metabolómica, la proteómica, y las técnicas masivas de alto rendimiento (high-throughput) permiten la adquisición de datos cuantitativos que se usan en la construcción y posterior confirmación del modelo propuesto.

Una forma frecuente de obtener datos de manera masiva es el uso de perturbaciones a gran escala (por ej. mediante el uso de RNAs de interferenciaiRNAs) así como de robots y sensores automáticos. No obstante, estos métodos son aún bastante incipientes y no están exentos de dificultades. A modo de ejemplo, recientemente se ha descrito que al comparar las secuencias de RNA obtenidas de linfocitos B humanos de 27 personas con las secuencias de DNA a partir de la cuales esos RNA se transcriben, surgen más de 10.000 sitios exónicos donde las secuencias de RNA no coinciden con las del DNA, encontrándose 12 categorías de discordancias que, al parecer, no son aleatorias ( $\mathrm{Li}$ et al., 2011). No obstante lo anterior, estas RDD
(RNA-DNA Differences) pueden ser el resultado de errores sistemáticos producidos durante los procedimientos de secuenciación. Otra posible fuente de error se relaciona con la existencia de secuencias similares en el genoma humano, lo que hace que sea difícil determinar el origen de una secuencia corta de RNA respecto de la secuencia específica de DNA desde la que fue transcrita. Más recientemente, los métodos de análisis estadístico de la información derivada de tales experimentos han sido objeto de escrutinio (Check Hayden, 2012). A pesar de lo anterior existen pocas dudas acerca de que los métodos mejorarán su rendimiento, lo que permitirá en un futuro no muy lejano despejar dudas como las descritas. Dicho mejoramiento y la confirmación independiente de los hallazgos (por más de un grupo de trabajo) son imprescindibles para asegurar la calidad de los datos.

Es difícil prever el impacto de la biología de sistemas en la comprensión delo que es una célula, y por extensión un ser vivo, una cuestión que no es más fácil por el hecho de que, como se ha indicado, no existe un consenso firme en cuanto a lo que se entiende por biología de sistemas", aunque, como ha señalado Kirschner, "todos parecen saber de que se trata cuando la vemos"(Nurse y Hayles, 2011).Los diversos atributos $y$ enfoques metodológicos asociados con la biología de sistemas, su desarrollo y aplicación a la biología celular, pueden ser determinantes para lograr una mejor comprensión del funcionamiento celular.

Reduccionismo Vs Holismo: ¿Antagónicos o Complementarios?

Las discusiones sobre la biología de sistemas hacen, frecuentemente, una distinción entre enfoques holísticos y reduccionistas como se ha mencionado antes. No obstante tanto las explicaciones científicas, como los métodos que se usan para producir esas explicaciones, parecen ser de naturaleza esencialmente reduccionista. Sin embargo, aunque es difícil imaginar una investigación científica o una explicación que sea no reduccionista, es importante considerar el comportamiento de los sistemas completos para entender cómo las interacciones y los procesos generados por componentes que actúan en los niveles "inferiores", se ven limitados por funciones que operan en los niveles superiores de un sistema cualesquiera. Con frecuencia los holistas objetan la dominancia de las explicaciones moleculares; no obstante, las explicaciones más útiles en biología celular deben hacerse en términos moleculares, porque son las moléculas los componentes más relevantes del nivel en que se descompone la función y la organización celular. Sin embargo, no 
todas las explicaciones en biología son moleculares, como por ejemplo los procesos del desarrollo ontogénico que pueden explicarse en términos de comportamiento de las células, y la neurobiología en términos de la actividad de las redes neurales. Del mismo modo, algunas ideas de la biología celular no pueden surgir de explicaciones estrictamente moleculares (Nurse y Hayles, 2011). En resumen, a pesar de que buena parte de los avances en nuestra comprensión acerca del funcionamiento de los organismos vivos descansa en avances realizados desde la bioquímica y la biología molecular (por ej. clonamiento y secuenciación), el entendimiento de muchos procesos de "orden superior" (homeostasis, mantención de la integridad celular, generación de patrones espaciales y temporales, señalamiento inter e intracelular, "memoria" celular) ha resultado esquivo (Nurse, 2008).

Un enfoque de la biología de sistemas ha consistido en hacer hincapié en las funciones biológicas generales expresadas en los diferentes niveles de organización biológica, como los organelos, la célula, los tejidos, los órganos $\mathrm{y}$, finalmente, el organismo. Como se dijo antes, el nivel de la célula ocupa una posición particularmente importante ya que es la unidad más simple que exhibe las características de lo vivo (Maturana y Varela, 1998; Brenner, 2010), por lo que entender la función biológica a nivel de la célula nos acerca a una mejor apreciación de la naturaleza de lo vivo. Los diferentes niveles o unidades de organización desde los organelos hasta el organismo, generalmente se describen en términos de comportamientos teleonómicos, es decir, comportamientos aparentemente útiles (dotados de algún propósito). Como ejemplos de esos comportamientos útiles pueden mencionarse la homeostasis y la mantención dela integridad de la organización, la generación de un orden espacial y temporal, la comunicación dentro y entre las unidades de organización, y la reproducción de esas unidades. Una perspectiva posible es entender cómo esos comportamientos se generan en las diferentes unidades de organización, por lo general en términos de las moléculas y de las interacciones entre las moléculas. Esta visión de la biología de sistemas destaca las funciones biológicas generales de la unidad biológica relevante y es un enfoque que abarca una serie de disciplinas tradicionales como la fisiología y la genética (Nurse y Hayles, 2011). Otro enfoque, diametralmente opuesto, es considerar que no es posible deducir modelos de funcionamiento a partir del comportamiento de un sistema dado, (por ejemplo una célula) y que ese comportamiento debe ser deducido a partir de los componentes del sistema y de sus interacciones (Brenner, 2010).
La necesidad de comprender, por diversos medios y propósitos, las funciones biológicas generales de un organismo vivo conduce, naturalmente, a la consideración de aspectos ecológicos y evolutivos acerca de cómo ese organismo opera. Esto también se aplica a las células y, como consecuencia, los interesados en los enfoques sistémicos de la biología celular deben considerar cada vez más las perspectivas ecológica y evolutiva. La ecología es relevante para entender las relaciones de una célula con otras células y con su entorno físico y se aplica tanto a organismos unicelulares de vida libre como a las levaduras, los protozoos y las células en los tejidos. Las perspectivas ecológica y evolutiva pueden ayudar a entender cómo una célula ha llegado a funcionar del modo en que lo hace y mejorar el conocimiento de las presiones selectivas que operan respecto de ella (Nurse y Hayles, 2011).

Convirtiendo los Datos en Conocimiento (o como evitar la biología del "low input, highthroughput, no ouput") - Una traducción aproximada sería como sigue: bajo (poco) esfuerzo, alto rendimiento (en datos), ningún resultado (nada decomprensión.

Quizás el mayor desafío de la era post-genómica es dar significado a la impresionante cantidad de datos que diariamente se producen y publican en las más prestigiosas revistas de ciencia del mundo. Es precisamente esa demanda lo que distingue la investigación (acumulación de datos) de lo que llamamos propiamente ciencia (la profundidad de la interpretación de los datos y su efecto en nuestra manera de concebir el mundo -la construcción de cultura). Una forma de abordar este problema es a través de la biología de sistemas, aún cuando las opiniones en este sentido pueden ser dispares (ver por ej. la referencia 9). No obstante lo anterior, y a pesar de la tradición de la célula como un hecho más empírico que teórico, es necesaria una base teórica que permita el tránsito de la investigación a la ciencia, esto es convertir los datos en conocimiento.

Un modo de operar de uso corriente en la biología de sistemas es generar descripciones de conjuntos, es decir, recopilar datos que describen el comportamiento de un gran número de componentes. Esto es posible gracias, por una parte, a la aparición de tecnologías y métodos de análisis cada vez más refinados que producen, paralelamente y de forma masiva, colecciones de distintos tipos de datos, y al establecimiento de consorcios y bases de datos por otra. El enfoque canónico de tales colecciones de datos es la secuenciación del genoma completo de diversos organismos, lo que permite la descripción y comparación de los contenidos de genes para una amplia gama de ellos, facilitando el análisis genético molecular de los mecanismos 
biológicos, mucho más allá del limitado número de organismos modelo disponibles hasta antes de este tipo de enfoque (Nurse y Hayles, 2011).

Casi todos los seres vivos están compuestos por células. En este sentido, la secuenciación de los genomas es particularmente útil puesto que los genes ortólogos - secuencias (genes) presentes en diferentes especies, cuya similitud es resultado de tener un ancestro común - que son importantes para un fenómeno celular particular pueden estudiarse en varias especies distintas. Además, las células de distintos organismos, o de diferentes tejidos de un mismo organismo, ofrecen la oportunidad de estudiar la expresión y regulación de la actividad de genes ortólogos relacionados con fenómenos celulares específicos en una amplia gama de situaciones. Ejemplo de esto es la comparación entre los mecanismos de control del ciclo celular en levaduras y embriones de metazoos. Por otra parte, el conocimiento de genomas completos permite efectuar experimentos de eliminación de genes. Al efecto se han usado principalmente dos tipos de métodos; supresión sistemática de genes $\mathrm{y}$ bibliotecas de RNA de interferencia pequeños (siRNAs). La eliminación por completo de la función de un gen determinado facilita la asignación funcional y la comparación de las funciones de genes entre organismos sencillos, aun cuando la redundancia, o las funciones no previstas de las proteínas (moonligthing) pueden complicar la interpretación de los resultados. Los siRNAs son muy versátiles, ya que pueden emplearse en muchos organismos, pero presentan, en ocasiones, problemas de especificidad. Estos métodos se han usado con éxito, por ejemplo, en la identificación de todos los genes necesarios para la viabilidad de las levaduras S. cerevisiae y S. pombe (Nurse y Hayles, 2011). Otras descripciones de conjuntos que se usan actualmente incluyen los microarreglos (microarrays) para estudiar los tipos y niveles de RNA, la espectroscopía de masas para el estudio de las proteínas, y la espectroscopía de masas combinada con cromatografía para la evaluación de metabolitos.

La disponibilidad de conjuntos de bases de datos también permite la agrupación sistemática de genes con funciones relacionadas. Por ejemplo, los catálogos de genes que cuando se eliminan producen un fenotipo celular similar permiten identificar conjuntos de genes necesarios para procesos particulares. Del mismo modo, los transcritos que se comportan de manera similar, (por ej. que muestran un nivel máximo en una determinada fase del ciclo celular) revelan que esos RNAs tienen, al menos potencialmente, funciones relacionadas con la progresión a través del ciclo celular. Otra manera de agrupar es la construcción de redes basadas en productos génicos que interactúan entre sí. Este tipo de redes se puede estudiar utilizando métodos que "fijan" las interacciones (por ej. el método del doble híbrido y la inmuno precipitación) para evaluar si las macromoléculas (proteínas) están en contacto físico. También son importantes las interacciones catalíticas que resultan en cambios metabólicos o en modificaciones químicas, tales como la fosforilación, metilación y acetilación. Los enfoques bioquímicos se pueden complementar con ensayos genéticos de interacción de alto rendimiento, aunque estos no necesariamente proporcionan evidencia de interacción física directa entre los componentes. El uso de proteínas fusionadas con GFP (Green Fluorescent Protein) permite la identificación de componentes moleculares que co-localizan espacialmente, como indicadores de relaciones funcionales potenciales. Todos estos métodos permiten la detección de diversas redes que conectan componentes moleculares de la célula y pueden usarse para generar el total del interactoma celular.

Para muchos investigadores, la creación de redes de interacción es un logro importante dela biología de sistemas que tiene como objetivo establecer redes completas para los diferentes procesos celulares. Sin embargo, el logro de este objetivo puede requerir anotaciones muy sofisticadas para describir completamente cómo funcionan esas redes. A diferencia de otras redes, los vínculos de interacción en las redes biológicas pueden ser complejos estables o reacciones catalíticas transitorias, o pueden reflejar la naturaleza lógica de la interacción, por ejemplo, la representación de una retroalimentación negativa o positiva. La notación utilizada en las descripciones de la red debe ser capaz de reflejar esta complejidad. También es importante tener en cuenta el hecho de que los vínculos no son siempre un "cableado", sino más bien de naturaleza principalmente química, en que las conexiones se establecen mediante la difusión de un componente a otro. Estos vínculos químicos se pueden romper y rehacer fácilmente para conectar diferentes componentes y remodelar la arquitectura de la red (Bray, 1995).

Métodos cuantitativos y modelos ¿Qué hay de nuevo?

Los métodos cuantitativos, que implican el uso tanto de grandes conjuntos de datos como del modelamiento de esos datos, se utilizan con frecuencia en los enfoques de sistemas. Las colecciones masivas de datos generadas por ejemplo por micro-arreglos, han sustituido a las de carácter 
más cualitativo obtenidos con las técnicas tradicionales de la biología molecular, por ej. electro-transferencia de RNA y proteínas. Una cuantificación apropiada y confiable conduce a una mejor comprensión de los efectos del número de moléculas dentro de una célula sobre los procesos biológicos. Por ejemplo, en un reciente estudio realizado en células. humanas, se encontró que a pesar de la diferencia de densidad de genes entre los distintos cromosomas, el porcentaje de genes expresados por cromosoma es menos variable y que genes implicados en procesos biológicos relacionados se expresan a niveles más parecidos que aquellos con funciones claramente distintas (Toung et al., 2011). Algunos transcritos de genes en levaduras están presentes en un promedio de menos de uno por célula, lo que cambia nuestro punto de vista acerca de que la regulación es controlada por la acción de masas, lo que hace necesario dedicar mayor atención respecto de cuál es la influencia del "ruido" molecular sobre el funcionamiento de la célula para determinar, por ejemplo si el "ruido", y la variabilidad que éste genera entre las células, se usa con fines regulatorios (i.e. respuestas celulares a cambios ambientales) (Nurse y Hayles, 2011).

Respecto de lo anterior, las impresionantes mejoras en los lasers, en la fotodetección y en los componentes ópticos han permitido que lo que comenzó en 1976 con la detección de varias moléculas de un fluoróforo unidas a una proteína, se convierta en la detección de una sola molécula de fluoróforo tanto in vitro como en células en cultivo. No exento de problemas (el principal de ellos la autofluorescencia), el análisis al nivel de una molécula revela un cuadro algo distinto respecto de aquel obtenido a partir del comportamiento de conjuntos (promedios) de moléculas. Nuestras concepciones acerca de la expresión y regulación de los genes han cambiado de modo que ambos procesos resultan ser de naturaleza esporádica (estocástica), lo que resulta, por ejemplo, en que poblaciones celulares con genomas idénticos presenten variaciones en el número de copias de sus mRNAs y de sus proteínas. Ciertamente, lo anterior deja abierta la posibilidad de que el fenotipo de célula sea el producto de la actividad de una sola molécula (Li y Xie, 2011), lo que significa que existirá variabilidad fenotípica entre células que expresan exactamente los mismos genes (Eldar y Elowitz, 2010). Puesto de otro modo, es necesario que los modelos posibles de construir incluyan lo que tradicionalmente se ha considerado "ruido" como un componente relevante de la explicación del fenómeno considerado.
Respecto de los procesos bioquímicos existe una larga tradición de modelamiento, si uno considera que tan temprano como 1913 (casi un siglo) Michaelis y Menten propusieron un modelo para explicar sus observaciones respecto de la reacción catalizada por la invertasa. En la actualidad los procesos bioquímicos se modelan generalmente mediante la derivación de ecuaciones diferenciales destinadas a calcular el flujo a través de las vías, usando para ello estimaciones in vivo de las constantes de velocidad y de las concentraciones de los componentes relevantes. Críticamente, esto requiere disponer de datos de muy buena calidad para generar modelos útiles. Aunque el modelamiento en biología celular se ha vuelto más frecuente, en parte debido al aumento masivo en los datos disponibles y a la "migración" de científicos más inclinados hacia la biología teórica, hasta no hace mucho tiempo era practicado sólo por unos pocos investigadores (Nurse y Hayles, 2011). El distinguido biólogo evolucionista John Maynard Smith sostenía que el acto de pensar acerca de las ecuaciones de un modelo aclara en gran medida la comprensión de cómo funciona el modelo. En términos generales, aunque no siempre es el caso, existe en la biología la tendencia a producir modelos algo vagos que suelen presentarse resumidos a la forma de caricaturas; es útil someter esos modelos a la disciplina de escribir las ecuaciones con la esperanza que la necesaria reflexión al escribir las ecuaciones mejorará la comprensión de los supuestos del modelo y su dinámica.

La generación de modelos supone al menos dos problemas. Por una parte está la complejidad de las vías que se modelan, y por otra la dificultad para estimar los valores apropiados de las constantes de velocidad y la concentración de los componentes, las que generalmente se han determinado in vitro. Además, las vías metabólicas suelen ser complejas con muchas funciones redundantes, lo que refleja el hecho de que la evolución no conduce a las soluciones más eficaces y económicas. La selección natural actúa sobre células pre-existentes frecuentemente haciendo adiciones a vías previamente operativas, y estas adiciones aumentan la redundancia. En este aspecto el modelamiento en biología puede ser diferente del usado en física donde, tradicionalmente, existe un componente estético que impone buscar el modelo más simple y elegante para explicar un fenómeno. En biología a menudo hay más elementos en un modelo que los estrictamente necesarios (desde el punto de vista de la física), y algunos de esos elementos funcionan de manera redundante. Lo anterior implica un aumento de los grados de libertad disponibles, lo que resulta en la disminución de la confianza en el resultado del proceso de modelamiento. No obstante, es claro que 
esa redundancia resulta en que las redes de procesos en biología resultan ser extraordinariamente robustas. Esto pone énfasis en que sólo la adecuada comprensión del funcionamiento de una red permite intervenir en ella con propósitos por ej. biotecnológicos.

A pesar de las dificultades mencionadas, existen aproximaciones para resolverlas. Una de ellas es poner a prueba la sensibilidad de un modelo, haciendo variar los parámetros de las ecuaciones correspondientes, para asegurarse de que todavía funciona correctamente. Si el modelo es robusto, cuando se utilizan diferentes valores en las ecuaciones, entonces la confianza en él es consecuentemente mayor. Otra aproximación de utilidad es posible de usar cuando el proceso bajo estudio puede recapitularse in vitro. En efecto, aspectos importantes del control del ciclo celular pueden estudiarse en extractos concentrados de oocitos de Xenopus y otras células. En extractos de Xenopus, por ejemplo, los niveles de componentes bioquímicos pueden medirse y manipularse más fácilmente de lo que es posible en una célula viva. Otro enfoque es el de simplificar la red bioquímica que subyace a la función biológica de interés, aunque esto es útil sólo si se mantienen los elementos esenciales de ese proceso. La ventaja de la simplificación es que reduce los grados de libertad disponibles, haciendo más fácil el modelamiento y más confiables los resultados. (verNurse y Hayles, 2011 y la bibliografía para ejemplos específicos)

Gestión de la información intracelular o la tentación de la cibernética (información)

Hay quienes piensan que las redes y los modelos cuantitativos que las describen se relacionan estrechamente con la gestión de la información al interior de una célula (Nurse y Hayles, 2011). El reconocimiento de la importancia de la noción de información fue crucial en el inicio de la biología molecular, en particular en el tratamiento de cómo la información fluye desde los genes hasta las proteínas, aunque se aplica a todos los aspectos del comportamiento celular. De acuerdo con Nurse, muchas de las explicaciones más significativas de la biología celular se han hecho en términos de flujo de información, lo que implica la comprensión de cómo la célula percibe, procesa, almacena y utiliza la información en el contexto de una función biológica o fenómeno de interés (Nurse, 2008). En esta perspectiva, la vida de una célula consistiría en la percepción de información tanto interna como externa, la cual se procesa y comunica a diferentes partes de la célula. Naturalmente, la información puede almacenarse en un amplio rango de escalas temporales, desde escalas de largo plazo como las hereditarias, de mediano plazo, como en los circuitos de mRNA y la transcripción de los genes, y de corto plazo como por ejemplo en la transducción de señales. Asimismo, el procesamiento de la información resulta en distintos comportamientos celulares, coordinando las respuestas adecuadas a circunstancias cambiantes.

No obstante lo anterior, la noción de información es sólo una metáfora, y considerarla de manera literal puede conducir a errores que es lo que típicamente ocurre cuando conceptos originados en un campo disciplinario se usan en uno distinto (uno frecuente es el darwinismo usado por los cientistas sociales, que escasamente han leído a Darwin). La noción de información requiere de un emisor de una "señal" que codifica un mensaje, un receptor y un contexto en que el receptor da significado a la señal, lo que se evidencia muchas veces como un cambio conductual. Con mucha facilidad olvidamos que las descripciones que hacemos de los sistemas son sólo eso, descripciones. Si como consecuencia de la unión de un ligando a una proteína ésta se activa (o se desactiva) no necesitamos, para comprender ese fenómeno, describir que el ligando contiene alguna "información" relevante para la proteína con la cual interactúa. En el extremo, uno podría describir que las enzimas tienen una memoria extraordinariamente buena pues siempre se acuerdan de que molécula deben unir (el sustrato) y siempre catalizan con esa molécula de sustrato, de entre varias posibles, la misma reacción sin mencionar el hecho que la buena memoria les alcanza a las enzimas para percibir cuando son "engañadas" por alguna molécula parecida al sustrato. El concepto de información no puede, en modo alguno, reemplazar al de relación causal de producción, no obstante que se ha usado para decir que el DNA funciona como un dispositivo de almacenamiento de información digital, que el operón lac representa un circuito regulador de retroalimentación negativa o que las vías de señalización funcionan como interruptores binarios que sólo pueden estar en uno de dos estados (encendido/apagado).

Mediante la generación de conjuntos de datos, de redes y de modelos la biología de sistemas ofrece una oportunidad para comprender las relaciones causales de producción que dan cuenta de la vida de una célula. La caracterización cuantitativa de esa relaciones es clave para transitar desde los estudios descriptivos de los fenómenos biológicos hacia una mejor comprensión de cómo funcionan. La metáfora de la información en los sistemas biológicos es innecesaria. Lo que necesitamos preguntarnos es ¿qué moléculas interactúan con qué moléculas?, 
¿resultan esas interacciones en otras interacciones?, $¿$ en que lugar ocurren esa interacciones?, ¿en cuanto tiempo se producen esa interacciones?, etc. Ninguna de esas preguntas requiere de la noción de información para ser respondida.

¿Quo vadis cellula?

La célula es la unidad más simple que presenta las características de lo vivo y por lo tanto es probable que sea el nivel más eficaz para investigar cómo funciona aquello que se considera que está vivo. El concepto de célula fue "inventado" entre 1835 y 1860 en el ambiente de la biología alemana que buscaba desplazar al idealismo como forma de estudio de lo natural (Vial Correa, 1999). La noción de la célula en tanto unidad aparece explícitamente en Virchow quien expresa: "the cell is really the ultímate morphological element in which the reis any manifestation of life, and that we must not transfer the seat of real action to any point beyond the cell" - la célula es realmente el elemento morfológico esencial en el que hay alguna manifestación de la vida, y no debemos transferir el lugar (dominio) en que se asienta la acción real más allá de la célula - (Virchow, 1858). Ciertamente el énfasis está puesto, inevitablemente, en lo morfológico. Desde entonces, pasando por la revolución que significó el uso de la microscopía electrónica y de la separación de los organelos en el estudio de las células, hemos sido testigos de la aparición de numerosas y novedosas herramientas para adquirir datos cada vez más finos. Como es casi trivial, los nuevos métodos permiten imaginar nuevas preguntas. La unidad relativamente simple emanada de la escuela alemana ha resultado ser tremendamente compleja y, ciertamente, contiene aquello que constantemente ha escapado a nuestros esfuerzos por comprender. Los poderosos procedimientos disponibles en la actualidad permiten imaginar el funcionamiento y organización de las células como un conjunto de redes de procesos en el que el estudio de las interacciones, entendidas como relaciones causales de producción, resulta ser clave. El marco intelectual de la biología de sistemas proporciona una oportunidad para lograr una comprensión global de éstas y de aquello que distinguimos como vivo.

\section{Referencias}

1. BRAY, D. 1995 ProteinsMolecules as ComputationalElements in Living Cells.Nature 376: 307- 312

2. BRENNER, S. 2010 Sequences and Consequences. Phil. Trans. R. Soc. London B 356: $207-212$
3. CHECK HAYDEN, E. 2012 RNA StudiesUnderFire.Nature 484: 428.

4. ELDAR, A.; AND ELOWITZ, M. B. 2010 Functional Roles forNoise in GeneticCircuits.NatureVolume:467:Pages: 167-173

5. KIRSCHNER, M. W. 2005 Themeaning of systemsbiology. Cell 121, $503-504$

6. LI, G. N.; and XIE X. S. 2011 Central Dogma at the Single-MoleculeLevel in Living Cells. Nature 575: 308-315

7. LI, M.; WANG, I. X.; YUN LI, Y.; BRUZEL, A.; ALLISON, L; RICHARDS. A. L.; TOUNG, J. M; CHEUNG, V.G. 2011 Widespread RNA and DNA SequenceDifferences in the Human Transcriptome. Science 333: 53 - 58

8. MATURANA, H.; VARELA F. 1998 De Máquinas y Seres Vivos. Quinta Edición. Editorial Universitaria, Santiago, Chile. $137 \mathrm{p}$.

9. NOBLE, D. 2006 The Music of Life: BiologyBeyondtheGenome. Oxford: Oxford UniversityPress. UK. 176 p.

10. SAUER, U.; HEINEMANN, M.; ZAMBONI, N. 2007 GettingClosertotheWhole Picture. Science 316: 550-551.

11. NURSE, P.; HAYLES, J. 2011 TheCell in an Era of SystemsBiology. Cell 144: 850854

12. NURSE, P. 2008 Life, Logic and Information. Nature454: 424 -426.

13. TOUNG, J. M.; MORLEY, M.; LI, M.; CHEUNG, V. G. 2011 RNASequenceAnalysis of Human Cells.GenomeResearch 21:991-998

14. VIAL CORREA J. 1999 La Invención de la Célula.BiologicalResearch 32(4): 14-24

15. VIRCHOW R. 1858 Lecture I: Cells and theCellularTheory. In: CellularPathologyTranslatedfromthe 2nd Ed. by F. Chance. PrintedbyJ.E.Adlard, BartholomewClose, London p1-23 


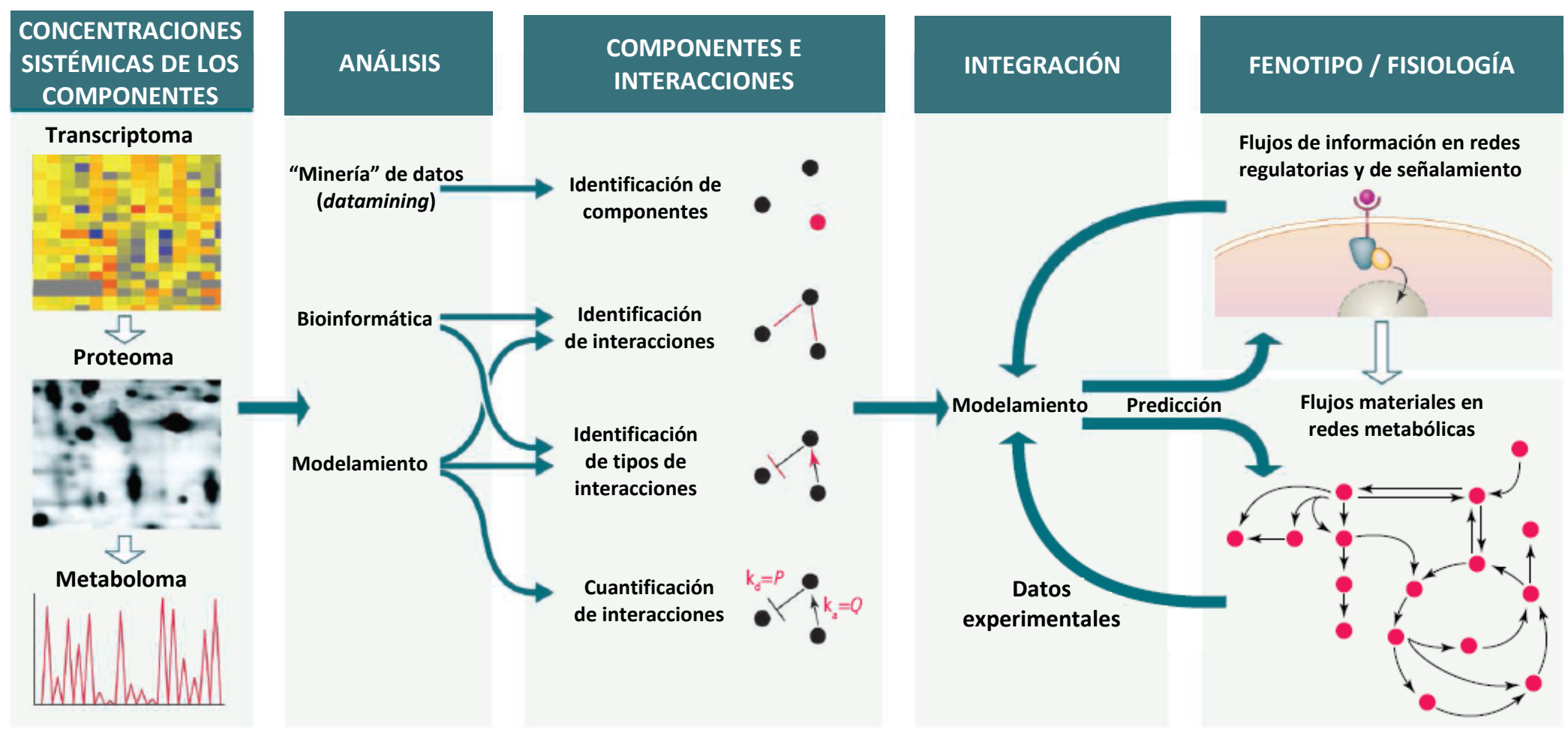

Figura 1.- Mapa de ruta en biología de sistemas. Las concentraciones de los componentes del sistema proporcionan los datos para inferir las interacciones de esos componentes utilizando métodos computacionales. El desafío para los métodos de modelamiento computacional es predecir el estado funcional de la red a partir las concentraciones para inferir la red de procesamiento de información que controla el estado funcional del sistema. (Adaptado de Sauer et al., 2007) 